$\square$ 원 저 $\square$

$$
\text { 하폐야 결핵의 임상적 고찰 }
$$

연세대학교 의 과대학 내 과학교실

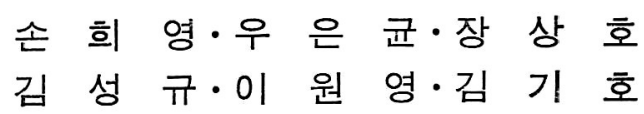

$=$ Abstract $=$

\title{
A Clinical Study on the Lower Lung Field Tuberculosis
}

\author{
Hee Young Sohn, M.D., Eun Kyun Woo, M.D., Sang Ho Chang, M.D., Sung Kyu Kim, M.D. \\ Won Young Lee, M.D., Kiho Kim, M.D. \\ Department of Internal Medicine, Yonsei University College of Medicine
}

\begin{abstract}
Lower lung field tuberculosis without concomitant upper lobe diseases occurred in $4 \%$ of patients with active pulmonary tuberculosis who were admitted to Severance Hospital from January, 1983 to June, 1984. In our study of 41 cases, the majority (71\%) were under 40 years of age and there were more women than men(M:F=1:2.4). Radiographic changes were found to be nearly equal in the right and left lung and in the basal and superior segments of the lower lobe. Involvement of the right middle lobe was rather interesting.

Extensive consolidation or collapse was found more often than upper lobar disease. Cavities were frequently found in the superior segment of both lower lobes. Tubercle bacilli were demonstrated on direct smear $(61 \%)$, on culture of sputum(37\%) and on smear of bronchial washing specimen $(2 \%)$. In about half of the cases, a tentative diagnosis was pneumonia, bronchial disease or pleurisy etc. Important clues to a diagnosis against pneumonia were hemoptysis, normal white blood cell count, cavitation, hilar lymphadenopathy and especially failure to improve with treatment for pneumonia. A lateral film of the chest was very beneficial, because it disclose hidden lesions such as collapse consolidation, infiltration and cavity which were not demonstrated by a routine chest P-A view. The results of treatment with antituberculous drugs were similar to those obtained in upper lobar tuberculosis.
\end{abstract}

\section{서 론}

결핵균은 임의적 호기성균(facultative aerobe)으로 서 폐첨부, 신장, 골피질(bony cortex)등 조직내 산 소포화도가 비교적 늪은 장기에 병변을 잘 일으키는 것으로 알려져 있다. 따라서 결핵이 하폐야에 국한되 어 발병할때 세균성 혹은 바이러스성 폐염이나 기관지 질환과 감별이 힘들때가 많고 정확한 진단을 얻을때까 지 의외로 오랜시간을 소요할 수가 있다.

그러므로 하폐약결핵에 다소 특징적으로 나타나는
임상상을 규명하여 동질환에 대한 index of suspicion 을 높힘으로써 초기에 진단, 치료에 임할 필요는 느끼 게 된다. 이에 저자등은 1983년 1월부터 1984년 6월까 지 연세대학교 의과대학 부속 세브란스병원에 입원하 였던 총 1,016예의 폐결핵환자중 하폐야결핵으로 진단 된 41예를 대상으로 각종 임상상을 검토하고 문헌을 비교고찰하여 몇가지 소견을 얻었기에 보고하는 바이다.

\section{관찰대상 및 방법}

관찰대상은 1983년 1월부터 1984월 6까지 1년 6개월 
Table 1. Number and Incidence of LLTB 41 Patients

\begin{tabular}{lcc}
\hline \hline & $\begin{array}{l}\text { total No. of } \\
\text { pulmonary TB }\end{array}$ & $\begin{array}{l}\text { No. of } \\
\text { LLTB patient }\end{array}$ \\
\hline male & 626 & 12 \\
Female & 390 & 29 \\
Total & 1,016 & $41(4 \%)$ \\
\hline M:F & $1.6: 1$ & $1: 2.4$ \\
\hline
\end{tabular}

\#LLTB: lower lung tuberculosis

동안 세브란스병원에 입원하였 던 폐결핵환자 1,016 예 중 객담 혹은 기관지세척액 도말 및 배양검사상 결핵 균 양성으로 하폐야결핵으로 진단된 41 예의 환자로 하 였다. 상엽에도 병변이 있는 경우는 제외하였다. 대상 환자의 전체 폐결핵환자에 대한 비율, 성별 및 연령분 포, 임상증상 및 이학적 소견, 초진당시 진단명, 동반 된 질환의 종류, 말초혈액백혈구수, 객담 결핵균검출 양상등을 조사하였다. 또 X-선사진을 검토하여 병변이 폐문을 지나는 가상적 수평선 아래에만 존재하는 예를 선택하였으며 P-A view 에서 불명확하고 측면사진에서 병변이 확인된 경우를 구분하였다.

치료경과를 추적하여 객담 결핵균 음전을 확인한 경 우는 19예에 불과했으나 참고로 분석하여 보았다.

\section{관 찰 성 적}

\section{1. 발생빈도}

관찰기간동안 세브란스병원에 입 원하였던 뎨결핵 환 자는 남자 626 예, 여자 390예, 총 1,016 예였으며 이중 하폐야 결핵 환자는 남자 12예, 여자 29예, 총 41예로 $4 \%$ 의 빈도를 나타내었다(Table 1).

\section{2. 성별 및 연령분포}

성별로는 남자가 12 예, 여자가 29예로 남녀비가 1 : 2.4 였으며 전체 결핵환자의 남녀비 $1.6: 1$ 과 비교해 볼때 여자에서 상대적으로 높은 빈도를 보였다(Table 1). 연령별로는 20 대가 18 예 $(43 \%)$ 로 가장 많았고 다 음이 30 대 7 예 $(17 \%), 40$ 대 8 예 $(19 \%)$ 등이었으며 전체 적으로 40 세이하가 27 예로 전체의 $71 \%$ 였다 (Table 2).

\section{3. 임상증상}

초진당시 자각증상은 Table 3 에 도시된 바와 같으며 이러한 증상들은 폐결핵, 세균성폐염 혹은 기관지 질 환에 공히 비특이적으로 나타날 수 있는 것들이어서 감별진단에 도움이 되지 못하였다.
Table 2. Age and Sex Distribution of LLTB Patients

\begin{tabular}{rrrr}
\hline \multicolumn{1}{c}{ Age } & Male & Female & Total $(\%)$ \\
\hline$<20$ & 2 & 2 & $4(9)$ \\
$21 \sim 30$ & 6 & 12 & $18(43)$ \\
$31 \sim 40$ & 1 & 6 & $7(17)$ \\
$41 \sim 50$ & 2 & 6 & $8(19)$ \\
$51 \sim 60$ & 1 & 1 & $2(6)$ \\
$61 \sim 70$ & 0 & 1 & $1(3)$ \\
$>75$ & 0 & 1 & $1(3)$ \\
\hline$>40$ & 3 & 9 & $12(29)$ \\
$<40$ & 9 & 20 & $29(71)$ \\
\hline & 17 & 29 & $41(100)$ \\
\hline
\end{tabular}

Table 3. Chief Complaints of the LLTB Patients

\begin{tabular}{lcc}
\hline \hline Symptoms & No. & $(\%)$ \\
\hline cough & 37 & $(90)$ \\
sputum & 26 & $(63)$ \\
fever & 13 & $(31)$ \\
chest pain & 10 & $(24)$ \\
dyspnea & 10 & $(24)$ \\
hemoptysis & 9 & $(21)$ \\
malaise & 5 & $(12)$ \\
night sweat & 4 & $(9)$ \\
weight loss & 4 & $(9)$ \\
\hline
\end{tabular}

\section{4. 이학적 소견}

이학적 소견은 Table 4에 도시된 바와 같으며 이러한 소견들도 역시 여러가지 호홉기질환에서 비 특이적으로 나타날 수 있는 것으로 오히려 기관지질환은 의심케 하는 경우가 많다.

\section{5. 검사소견}

말초혈액검사상 백혈 구수는 정상범위가 33 에 $(80 \%)$ 로쎠 일반세균성폐염과의 감별에 어느정도 도움을 준 것으로 사료된다(Table 5).

\section{6. 동반된 질환}

초진시 혹은 관찰기관중 동반되어 있는 것으로 발견 된 질환은 Table 6에 도시된 바와 같다. 이중 세균성 폐염은 복합감염의 예로 생각되었으며 기관지확장증은 
Table 4. Physical Findings of the LLTB Patients

\begin{tabular}{lcc}
\hline signs & No. & $(\%)$ \\
\hline rale & 14 & $(34)$ \\
ronchi & 10 & $(24)$ \\
not remarkable & 10 & $(24)$ \\
diminished breath sound & 9 & $(21)$ \\
wheezing & 2 & $(4)$ \\
bronchial breath sound & 2 & $(4)$ \\
\hline
\end{tabular}

Table 5. Leukocyte Count of the LLTB Patients

\begin{tabular}{lrr}
\hline $\mathrm{WBC}\left(/ \mathrm{mm}^{3}\right)$ & No. & $(\%)$ \\
\hline$<10,000$ & 33 & $(80)$ \\
$>10,000$ & 8 & $(20)$ \\
\hline & 41 & $(100)$ \\
\hline
\end{tabular}

Table 6. Associated Conditons of the LLTB Patients

\begin{tabular}{lcc}
\hline \hline condition & No. & $(\%)$ \\
\hline pneumonia & 5 & $(12)$ \\
diabetes mellitus & 3 & $(7)$ \\
lymphadenitis & 2 & $(4)$ \\
bronchiectasis & 2 & $(4)$ \\
pregnancy & 2 & $(4)$ \\
lung abscess & 1 & $(2)$ \\
kyphoscoliosis & 1 & $(2)$ \\
pleurisy & 1 & $(2)$ \\
\hline
\end{tabular}

기관지조영술로 동 질환을 진단, 치료하던중 객담배양 에서 결핵균양성이 밝혀진 예로서 어느쪽이 선행질환 이었을지는 확실히 알 수 없었다. 폐농양(포도상구균 성 ) 1 예는 당뇨병과 합병되어 있었으며 폐농양의 치료 가 거의 완료되어갈 즈음에 객담배 양에서 결핵균양성 으로 밝혀져 처음부터 복합감염되어 있었던 것으로 사 료된다. 척추만곡중 및 임신등은 합병질환이라기 보다 는 동반되어 나타난 상황이라고 생각되며 동질환과의 어떤 인과관계는 증명할 수 없었다.

\section{7. 초진당시 진단명}

세균학적 진단을 얻기전 병력, 증상과 이학적소견 및 X-선소견만을 토대토 내린 진단은 폐결핵이 20예
Table 7. Presumptive Diagnosis of the Patients

\begin{tabular}{lcc}
\hline \hline diagnosis & No. & $(\%)$ \\
\hline tuberculosis & 20 & $(49)$ \\
pneumonia & 13 & $(32)$ \\
bronchitis and/or & & $(10)$ \\
bronchiectasis & 4 & $(5)$ \\
pleurisy & 2 & $(2)$ \\
lung abscess & 1 & $(2)$ \\
lung cancer & 1 & $(100)$ \\
\hline
\end{tabular}

$(49 \%)$ 였고 나머지는 폐염 13 예 ( $32 \%)$, 기관지질환 4 예 $(10 \%)$, 홍막염 2 예 $(5 \%)$, 폐농양 1 예 $(2 \%)$, 폐암 1 예 ( $2 \%$ )등이었다 (Table 7 ).

\section{8. 병소의 분포}

우폐에 병소를 가진 환자는 20예, 좌폐 19예, 양측 성 병소를 가진예가 2예였다. 병소의 수는 모두 47 개 였으며 분엽 별로는 우중엽 (8), 우하엽 (12)중 상-하엽 구 2예, 폐저구 9예, 우하엽 전체 침습예가 6예였다. 좌폐는 설상구(1), 좌하엽(21)중 상-하엽구 7예, 폐 저구 6예, 좌하엽전체 침습예가 8예였다. 공동병소는 양측 모두 상-하엽구에 각각 4예씩, 폐저구에 좌우 각각 1 예 및 2예가 있었다(Table 8).

\section{2. 촉면사진의 이점}

정면촬영에서 병변이 확실치 않고 측면사진상 확인 했던 경우를 참고토 구분하였다. 이들 예는 41 예중 16 예 ( $38 \%$ ) 로써 그증 허 탈성 경 변 (collapse consolidation) 이 4예 및 침윤이 7 예였고 공동발견이 5 예 (12\%)였다 (Table 9).

\section{0. 결핵균 검출상황}

객담직접도말검사상 결핵균 양성예는 41 예중 25 예, $(61 \%)$ 로 비교적 높은 편이었고 배양에서만 균이 검출 된 예가 15 예 (37\%)였다. 이들중 상당수가 배 양결 과가 나오기까지 치료가 지연되었다. 1예는 기관지세척액도. 말상 결핵균 양성으로 진단되었다(Table 10).

\section{1. 치료에 따른 균유전상황}

환자의 추적의 불충분이나 객담채취곤란으로 균음전 상황을 추적할 수 있었던 예는 19예에 불과하였으나 
Table 8. Distribution of LLTB in 41 Patients

\begin{tabular}{llll}
\hline \multicolumn{1}{c}{ Right Lung } & & \multicolumn{1}{c}{ Left Lung } \\
\hline Middle lobe & 8 & Lingula & 1 \\
Superior segment & $2(4)$ & Superior segment & $7(4)$ \\
Basal segment & $9(2)$ & Basal segment & $6(1)$ \\
Whole lower lobe & 6 & Whole lower lobe & 8 \\
Total & 25 & Total & 22 \\
\hline No. of patients & 20 & No. of patients & 19 \\
\hline
\end{tabular}

Bilateral: 2 cases

Numbers in parenthesis indicate cavitary lesions.

Table 9. Advantages of the Lateral Films

\begin{tabular}{lcc}
\hline \hline Advantage & No. & $(\%)$ \\
\hline discovery of hidden leison & 11 & $(26)$ \\
collapse consolidation & 4 & \\
infiltration & 7 & \\
detection of cavitary leison & 5 & $(12)$ \\
\hline & $16 / 41$ & $(38)$ \\
\hline
\end{tabular}

Table 10. Yield Rate of AFB in LLTB Patients

\begin{tabular}{lcc}
\hline \hline method & No. & $(\%)$ \\
sputum smear & 25 & $(61)$ \\
sputum culture & 25 & $(37)$ \\
bronchial washing smear & 1 & $(2)$ \\
\hline & 41 & $(100)$ \\
\hline
\end{tabular}

Table 11. Duration for Sputum Negative Conversion

\begin{tabular}{ccc}
\hline \hline duration $(\mathrm{mo})$ & No. of Pt. & $(\%)$ \\
\hline 2 & 7 & $(37)$ \\
2.5 & 2 & $(11)$ \\
3 & 4 & $(21)$ \\
4 & 2 & $(11)$ \\
6 & 1 & $(5)$ \\
$>6$ & 3 & $(15)$ \\
& 19 & $(100)$ \\
\hline
\end{tabular}

그중 7 예 $(37 \%)$ 가 2 개월이 내에 음전되었고 13 예 $(80 \%)$ 가 4 개월이내에 음전되었다. 3 예는 6 개월 경 과시에도 음전되지 않아 약제내성검사를 시행한바 1예에서 INH,
$\mathrm{EMB}$ 및 Rifampin 에 모두 내성이 있어 $\mathrm{INH}, \mathrm{PZA}$, PAS, 1321 및 SM으로 치료하였다(Table 12).

\section{고안 및 고찰}

하폐야 결핵은 1886 년 $\mathrm{Kidd}^{1}$ 가 폐하엽의 상-하엽 구(superior sergment)에 결핵이 호발할 수 있다는 기 술과 함께 처음으로 보고하였고 1920년대 이후에는 상 당히 많은 보고들이 속출하였다. 재감염형의 결핵이 폐첨부나 쇄골하부에 호발하는 임상적 특성때문에 하 폐야의 병변을 감별진단시 우선순위에 두지않기 때문 이었는지는 모르나 근대에 이르기까지 전체 폐결핵의 비교적 소수에서만 하폐야결핵이 인정되고 있다.

하폐야결핵의 정의는 훙부 정면활영상 폐문부를 횡 단하는 가상적인 수평선을 중심으로 그 이하의 폐야에 발생하는 폐결핵을 말한다 ${ }^{2}$. Ossen ${ }^{3}$ 은 이를 상엽에는 병변이 전혀없는 "pure group", 상엽에도 병변이 있 는 "impure group"으로 구분하기도 하였다. 그러나 저자등은 하폐야결핵이 가지는 임상상의 특징이 있나 를 좀더 확연히 구분해 보기 위해 상엽의 병변이 있는 경우를 모두 배제하였다 보고자에 따라 명명법은 조금 씩 차이가 있어 basal tuberculosis(4), Lower lobe tuberculosis ${ }^{5}$, parahilar or perihilar tuberculosis 등 $2,4,5)$ 의 동의어가 있다. 하폐야 결핵빈도는 보고자에 따라 차이가 많아서 Reisner ${ }^{6}$ 의 $0.03 \%$, Segarra ${ }^{2}$ 의 $0.85 \%$ 로부터 Romendick ${ }^{7}$ 의 $2.7 \%$, Berger 등 ${ }^{8}$ 의 $7 \%$ 에서 Ross ${ }^{91}$ 의 $30 \%$ 에 이르기까지 매우 다양한데 이는 그 대상환자군의 선택에 의한 차이인 듯하다. community hospital 에서의 빈도와 Ross 의 경 우처럼 결핵 요양원에서 관찰한 경우와는 차이가 있을 것으로 추정 된다. 저자등은 $4 \%$ 정도의 빈도이었으며 이는 국내보 고인 양등 ${ }^{10)}$ 의 $1.24 \%$ 나 안등 ${ }^{111}$ 의 $2.22 \%$ 에 비해 다소 
높은 편이나 입원환자만을 대상으로 하였기 때문에 전 체 결핵환자중에서의 빈도를 대변한다고 보기는 어렵 다. 성별로는 대다수의 보고자 들 $1,5,6)$ 이 여성에서 호 발하는 것(남녀비 $1: 2$ 내지 $1: 18$ )으로 보고하고 있 으나 Berger 등 ${ }^{8)}$ 은 오히려 남자에 더 많은 것 $(63 \%)$ 으로 보고하였다. 저자등은 남녀비가 $1: 2.4$ 이었다. 연령분포는 Segarra 등2)의 경우 40 세 미만이 $89 \%$, Romendick ${ }^{7}$ 은 $91.5 \%$ 라고 했고 저자등의 예에서도 40세만이 $71 \%$ 이며 그중 20 대가 가장 많고 $(43 \%)$, 다 음이 40 대 $(19 \%), 30$ 대 $(17 \%)$ 순이었다. 국내의 양 등 ${ }^{10}$ 도 20 대에 가장 많고 10 대, 30 대, 40 대에 비숫한 빈도를 보인다고 하였으나 안등11)의 경우는 소아로부 터 10대, 20대, 30대, 40 대의 순으로 연령이 적을수 록 하폐야결핵의 빈도가 많은 것 같다고 하였다. 임상 증상은 하폐야결핵에 특징적인 것은 없고 기관지 결 핵이 합병된 탓인지 $(42 \% \sim 90 \%)^{8)}$ 모르나 기관지염이 나 기관지확장증등을 의심케 하는 rale이나 ronchi, 호흡음감소등이 관찰되었고 타문헌에서도 이와 유사한 양상이 있음을 보고하였다,12). 하폐야결핵은 우폐에 더 호발하는 것으로 보고된 예가 많다 $1,6,7,13)$. 그러나 Berger 등8)은 좌, 우폐의 분포가 균등하다고 하였고 저자등의 41예에서도 좌폐 19예, 우폐 20예, 양쪽성 2 예로 좌우폐의 차이는 뚜렷치 않았다.

Pratt-Johnson ${ }^{5)}$ 을 제외한 대부분의 보고자들 $\left.3,13,14\right)$ 은 하엽의 상-하엽구가 폐저구보다 하폐야결핵의 병 소가 훨씬 호발한다고 하였다. 그러나 저자등의 예에 서는 우중엽 병소가 다소 많은 것이 특징이었고 하엽 의 상-하엽구와 폐저구에는 비교적 균등한 분포률 보 이나 다만 상-하엽구에는 공동병소가 많은 편이라고 볼 수 있겠다. 하폐야결핵의 X-선소견은 상엽결핵과 많이 다르며 폐엽과 비슷한 소견 ${ }^{2,5)}$ 을 나타내며 상엽 에 비해 경변(consolidation)이 훨씬 융합성(confluent)이며 광범위한 편이다. 저자등의 경우에도 하엽전 체가 침습된 예가 총 47 개병소중 14 개 병소나 되었다. 또한 공동이 많은 것도 특징인데 Berger 등 ${ }^{8)}$ 은 $48 \%$, Rothstein ${ }^{14)}$ 은 $60 \%$ 정도에서 공동을 관찰하였다고 하 였고 Sokoloff ${ }^{15)}$ 는 임상경 과중 삼출성병변 (exudative leison)이 급속히 공동화되는 것을 관찰할 수 있었다. 저자등은 총 47 개 병소중 11 개의 공동을 관찰하였는데 이중 각각 4개씩이 양측 상-하엽구에 있었고 좌, 우 폐저구에 각각 1예, 2 예씩 있었다. 저자등의 예에서 훙부 정면 X-선상 특기할만한 병변이 확실치 않고 측 면사진상 이상소견을 발견한 예가 41예중 16 예 (38\%) 나 되어 측면사진의 중요성을 인정할 수 있었다. Be- rger 등8)도 하폐야에 X-선상 폐염양소견이 보일때 백 혈구수가 정상범위면 결핵성으로 비증을 두자고 하였 다. 저자등에서도 백혈구수 $10,000 / \mathrm{mm}^{3}$ 미만이 41 예중 33 예 $(80 \%)$ 였다.

물론 이것이 큰 판단기준이 될수는 없으나 감별진단 의 보조수단으로 어느정도 가치가 있는듯하다. 하폐야 결핵은 임상증상이나 X-선소견 만으로 세포성 혹은 바 이러스성 폐염과 구별이 힘들고 다만 공동이 보일때 결핵의 진단을 좀더 선호할 수 있을 것이다. 저자등의 예중 초진시 결핵으로 진단했던 경우가 20 예 $(49 \%)$ 였 으며 나머지는 폐염 13예 (32\%), 기 관지질 환 4 예 $(10 \%)$ 등이었다. 결핵으로 진단된 20예증에도 내원이전 타질 환으로 치료하여 호전되지 못한 기왕력이 단서가 된 경우가 많았다. 이러한 비특이적인 소견때문에 하폐야 결핵의 진단에는 객담결핵균검출이 필수적이다. Berger 등 ${ }^{8)}$. Hamilton ${ }^{12)}$, Sokoloff ${ }^{15)}$ 및 Gordon 등 ${ }^{16)}$ 은 하폐야결핵시 객담직접 도말상 양성율이 낮으므로 다수 의 가검물을 반복검사하거나 기관지 세척액검사등을 요한다고 하였다. 저자등은 41 예증 25 예 $(69 \%)$ )에서 도 말양성 15 예 $(37 \%)$ 는 배양양성 1 예 $(2 \%)$ 는 기관지 세 척액 도말양성이었다. 배양에서만 균이 검출된 15 예중 일부는 배양결과 확인시까지 치료가 지연되었다. 이러 한 예에대해 Weidman 과 Campbell17)은 환자와의 접 촉의 기왕력, 증상 및 $\mathrm{X}$-선등을 참작하여 항결핵요법 을 일단 시작하라고 하였다. Segarra', Reisner's), Fernandez ${ }^{18)}$ 및 Chambers 등 ${ }^{19)}$ 은 당뇨병, 임신, 규 폐증, 척추만곡증등이 있을때, 또 간호원이나이리 노 령 등히에서 하폐야결핵이 호발한타고 하였으나 이들 질 환과의 인과관계는 아직 규명되지는 않았다. 당뇨병은 Segarra 등 2 은 $8.5 \%$, Berger 등 ${ }^{8)}$ 은 $11 \%$ 의 늪은 이환 율을 보였으나 양등미의 예에서는 없었다고하며 안등1ㅣ 은 $3.2 \%$ 로섯 전체 결핵환자에서의 $2.8 \%$ 와 대차가 없 었다고 하였다. 저자등에서도 당뇨병 3 예 $(7 \%)$, 임신 12 예 (4\%), 척추만곡증 1 예 $(2 \%)$ 등이 있었으나 하폐야 결핵과의 인과관계 는 규명하지 못하였다. 그러면 하폐 야 결핵의 발병기전은 무엇일까? 아직 확실치는 않으 나 뗯가지 설명이 있다. 가장 지지를 받고 있는 설은 결 핵으로 괴사된 폐문임파절이 경기 관지천공 (transbronchial perforation)을 일으켜 부근의 폐로 균이 파급 된다는 것이다2,21). 이러한 상황에서는 당연히 기관지 결핵의 병발이 있을 것으로 추측할 수 있으며 이에 대 한 상당예가 보고된바 있다 ${ }^{13)}$. 저자등의 경우 ronchi 가 심했던 예중 4예에 기관지경 검사를 시행하여 4 예 모두에서 기관지결핵이 발견되었으며 나머지 예에서도 
기관지경검사를 시행했다면 더 많은 기관지 결핵을 발 견했을 것으로 생각된다. 다음으로는 하엽, 특히 상하엽구의 환기 (ventilation)를 문제로 든다. 호흡시 폐 의 하엽과 상엽의 후상엽구는 주로 횡격의 운동에 의 해 팽창되며 상엽의 전상엽구, 폐첨구 및 중엽을 주로 늑골의 운동에 의해 움직인다라. 주로 횡격에 의해 팽 창되는 폐의 부위는 개인차가 있으나 대개 제 5 늑골부 위까이며 따라서 하엽의 상-하엽구가 대충 횡격운동 영향견의 경계부위에 해당한다. 따라서 정상호흡시 환 기비율이 가장 적다는 사실이 이 부위에 하폐야결핵의 호발과 어떤 상관관계를 가지리라고 보고있다6,21,23). 정상호흡에서 남자는 횡격운동이, 여자는 늑글운동이 주된 작용을 하므로 여자에서 횡격운동이 상대적으로 적다는 사실과 횡격운동으로 팽창되는 폐구획의 상한 이 여자에서 남자보다 낮은 부위에 있을 것으로 추론 할 때 다른 모든 요인이 (접종물의 양 및 환자의 면역 능의 상태) 동일한 경우 하폐야결핵의 발병확율이 여 자에 더 많을 것이라고 추정할 수 있다.

그외에도 폐문임파절로부터의 임파액의 역행성관류 등 ${ }^{24)}$ 의 기전으로 설명하기도 한다.

진단과 치료에 있어 폐염과 유사한 임상증상이 있고 하폐야에 병변이 있으면서 아급성 혹은 만성경 과를 취 하면 일단 의심해보아야 한다. 중요한 단서가 되는 것 으로는 혈담, 정상백혈 구수, 공동병소의 발견, 폐문임 파선종대, 훙막삼출, 상엽에 결핵병변이나 치유된 반 흔이 있을때, 일반 항생제치료에 반응을 나타내지 않 는 경 우등이다 ${ }^{8,10,11,25)}$.

대부분의 보고 ${ }^{13,14,24)}$ 에서 치료에 대한 반응은 타부 위의 결핵과 비슷하다고 한다. 저자등의 경우에는 균 음전에 대한 추적조사가 잘되지 못하여 도움이 될만한 결론을 얻지못하였으나 추적된 19예중 13 예 $(80 \%)$ )에서 4 개월이내에 배양음성이 인정되었고 3 예 $(15 \%)$ 에서는 6 개월 경과시에도 음전듸지 않아 약제 내성검사를 시행 한 결과 1예에서 INH, EMB 및 Rifampin 에 모두 내 성이 있음을 발견하여 INH, PAS, PZA 1321 및 streptomycin 으로 치료증이다. 또 X-선 사진으로 경과를 관찰할 때 폐문부에 반흔을 남기거나 하엽에 기관지맥 관상의 혼잡을 나타내어 병변의 호전내지 소실여부를 명료하게 판단하기 힘든 문제도 있었다.

\section{결 론}

저자등은 1983년 1월부터 만 1년 6개월간 세브란스 병원에 입원하여 하폐야결핵으로 진단된 41 예를 관찰
하여 다음과 같은 결론을 얻었다.

1) 전체 폐결핵 환자에 대한 하폐야결핵의 비율은 $4 \%$ 정도였고 남녀비는 $1: 2.4$ 였다. 연령별로는 20 대에 가장 많았고 전체 환자의 $71 \%$ 가 40 세미만이었다.

2) 임상증상과 이학적소견상 하폐야결핵의 특징이라 고 할만한 것은 없었고 ronchi, 천명음등 기관지질환을 의심케하는 소견이 다소 많은 편이었다.

3) 말초혈액백혈구수는 $80 \%$ 에서 정상범위였고 객담 결핵균검 사는 도말양성이 $61 \%$, 배양양성이 $37 \%$, 기 관지세척액 도말양성이 $2 \%$ 였다.

4) 병소의 부위는 좌우폐에 비교적 균동하였으며 폐 저구, 하엽의 상-하엽구 및 하엽전체침습예가 비슷한 숫자였고 공동은 주로 양측 상-하엽구에 많았다.

5) 측면 X-선상 발견된 병소가 41 예중 16예 $(40 \%)$ 로 측면선의 중요성을 인정할 수 없었다.

6) 추적조사가 가능랬던 19예중 13예 (68\%)가 4개월 내 균음전이 되었고 3 예 $(15 \%)$ 는 6 개월 경 과시에도 음 전되지 않았다.

\section{REFERENCES}

1) Kidd P: On basal tuberculosis phthisis. Lancet $2: 615,1886$.

2) Segarra F. Sherman DS and RodriguezAguero $\mathrm{J}$ : Lower lung field tuberculosie. Am Rev Resp Dis 87:37, 1963.

3) Ossen EZ: Tuberculosis of the lower lobe. N Engl J Med 230:693, 1944.

4) Busby LF: Basal tuberculosis. Am Rev Tuberc 40:692, 1939.

5) Pratt-Johnson, JH: Observations on lower lobe tuberculosis. Br J Dis Chest 53:385, 1959.

6) Reisner D: Pulmonary tuberculosis of the lower lobe. Arch Intern Med 56:258, 1935.

7) Romendick SS, Friedman B and Schwarz HF: Lower lung field tuberculosis. Dis Chest 10:481, 1944.

8) Berger $W H$ and Granada MG: Lower lung field tuberculosis. Chest 65:522, 1974.

9) Rass EL: Tuberculosis in nurses: A study of the disease in sixty nurses admitted to the Manitoba sanatorium. Can Med assoc J22:347, 1930.

10) 양정규, 김현남, 서광용, 윤춘열, 허진득 : 폐하야 
결핵의 임상적 고찰. 대한내과학희잡지 $9: 186$, 1976.

11) 안득수 : 폐하야 결핵 (286예)의 임 상적 관찰. 대한 내 과학회잡지 9:757, 1976.

12) Hamilton CE, Fredd $H$ : Lower lobe tuberculosis: A review. JAMA 105:427, 1935.

13) Parmar MS: Lower lung field tuberculosis. Am Rev Resp Dis 96:310, 1967.

14) Rothstein E: Pulmonary tuberculosis involving the lower lobes. Am Rev Tuberc 59:39, 1949.

15) Sokoloff MJ: Lower lobe tuberculosis. Radiology 34:589, 1940.

16) Gordon BL, Charr R., Sokoloff MJ: Basal pulmonary tuberculosis: results of treatment. Am Rev Tuberc 49:432, 1944.

17) Weidman WM, Campbell HB: Lower lobe tuberculosis. Am Rev Tuberc 36:525, 1937.

18) Fernandez MZ, Nedwicki EG: Lower lung field tuberculosis. Mich Med 68:31, 1969.
19) Chambersm JS: Tuberculous cavities of the lower lobe. Results of treatment in 103 patients. Am Rev Tuberc 63:625, 1951.

20) Ostrum HW, Serber W: Early roentgen recognition of lower-lobe tuberculosis. Radiology 53: $42,1949$.

21) Andosca JB, Foley JA: Basal Tuberculosis. J Thorac Surg 12:259, 1943.

22) Keith A: The mechanism of respiration in man, in Hill, Leonard: Further advance in physiology, New York, Longman, Green \& Co., 1909.

23) Fries JW, Groves W: Lower lobe tuberculosis. Mich Med 54:1310, 1955.

24) Viswanathan $R$ : Tuberculosis of the lower lobe. Br Med J 2:1300, 1936.

25) 김경오, 이상용, 김해성, 김기호, 이성동, 박노 춘 : 결핵성폐염의 임상적 관찰. 대한내 과학회잡지 $27: 467,1984$. 